\title{
Introduction: change and persistence in contemporary economics
}

\author{
Jakob Kapeller ${ }^{1 * *(1)}$ and Daniel Meyer ${ }^{2}$ (D) \\ ${ }^{1}$ Institute for Socio-Economics, University of Duisburg-Essen; Institute for Comprehensive Analysis of the Economy ICAE, \\ Johannes Kepler University, Linz; and ${ }^{2}$ Max Planck Institute for the Study of Societies, Cologne \\ ${ }^{\star}$ Corresponding author. E-mail: jakob.kapeller@uni-due.de
}

The financial crisis of 2007-2008 not only shook the global economy, but also directed attention to its intellectual underpinnings in modern economics. To investigate "where it went wrong," as a 2009 cover of The Economist put it, many scholars have become concerned with the development of economics as a discipline, the role of economic knowledge in political and practical contexts, and the impact of blind-spots in standard economic theory. Building upon the pioneering works of Deirdre McCloskey (1985), Philip Mirowski (1989), Michel Callon (1998), Donald MacKenzie (2006), Marion Fourcade (2009), and Mary Morgan (2012), these scholars have continued analyzing contemporary economics as an academic profession and as a particular way of thinking about social issues. In doing so, they have not only moved forward the classical debates on the peculiarity and performativity of economics, but have also established new domains of research by focusing on the inner workings of central banks, investment banking, or the education of future economists. Some newer review articles and book collections bear witness to the output of this vibrant and expanding field (e.g., Hirschman and Berman 2014; Boldyrev and Svetlova 2016; Kapeller, Pühringer, Hirte, and Ötsch 2016; Maeße, Pahl, and Sparsam 2017; Fourcade 2018; Godechot 2018; Pahl 2018; Schmidt-Wellenburg and Lebaron 2018). In addition, the advent of large-scale citation data has also led to increasing interest for such questions within the economic mainstream, where new forms of the "economics of economics" have become visible over the past years (e.g., Hamermesh 2018; Heckman \& Moktan 2018).

While indeed a newfound interest of many scientists, research on economics and economic knowledge is actually a classic topic in the history of science - not only due to its political importance, but also because of a marginalized, but still resilient, tradition of studying the history of economic thought as a subject in its own right (see Blaug 2001). Here, economics is described as a highly contested and stratified discipline with a strong cumulative research program at its core that has pushed "dissident" or "heterodox" economists to the edge of the discipline. Accordingly, the academic divide between orthodox, mainstream, and heterodox economics (Colander, Holt, and Rosser 2004; Dobusch and Kapeller 2009) and its impact on the distribution of scientific power are genuine research interests for many (heterodox) economists.

With the rise of the social studies of science - further accelerated by the economic downturn of 2008-2009 - the "old" history of economic thought is now supplemented and extended by the "new" sociology of economics focusing more on contemporary economics and its effects on policy, society, and the economy at large. As a matter of fact, all contributions in this issue of Science in Context explore research questions at the intersection of sociology, economics, and the history of economic thought.

\footnotetext{
(C) The Author(s) 2020. This is an Open Access article, distributed under the terms of the Creative Commons Attribution licence (http:// creativecommons.org/licenses/by/4.0/), which permits unrestricted re-use, distribution, and reproduction in any medium, provided the original work is properly cited.
} 
Even though current research in the sociology and history of economic thought addresses a broad spectrum of topics, it mostly focuses on the social structure, culture, and discourse of economics based on case studies or other qualitative methods. While we do not oppose qualitative research per se, we are concerned that the sociology and history of economics do not yet take full advantage of the many opportunities that have come with the advent of computational methods and novel data sources. In our view, sociologists and historians of economics would benefit from quantitative methods since they provide a more complete picture of economics and its social stratification than qualitative or historiographic methods would otherwise do (Edwards, Giraud, and Schinckus 2018). As bibliometric and other scientometric data are easily accessible in the twenty-first century, we encourage researchers to actively engage with them.

Accordingly, most articles in this topical issue concentrate on either bibliometric or other scientometric data allowing for a broader and more robust analysis of economics. By compiling quantitative papers, this topical issue demonstrates the potential of a more data-driven approach to the history, economics, and sociology of economics that will contribute to a new development tentatively referred to as a "quantitative turn" in the historiography of economics (Edwards, Giraud, and Schinckus 2018; Cherrier and Svorenčík 2018).

What we consider a best-practice example for both quantitative and transdisciplinary research is the 2015 ground-breaking study on the "superiority of economists" by Marion Fourcade, Etienne Ollion, and Yann Algan. Analyzing citation patterns, surveys, and professional associations in economics, political science, and sociology, the study finds economics to be the most dominant and, at the same time, most isolated discipline among the three social sciences. Hence, it comes as no surprise that this study inspired many of the contributions in our topical issue which, in turn, could be read as reproductions and extensions of its original findings. This is especially true for the first article to the topical issue, authored by Matthias Aistleitner, Jakob Kapeller, and Stefan Steinerberger, which analyzes citation patterns of five disciplines: economics, political science, psychology, sociology, and physics. It finds that economists' citation behavior systematically differs from patterns found in other disciplines due to a higher level of internal stratification, a stronger role of institutional incentives, and a decidedly lower degree of paradigmatic and disciplinary openness. In a similar spirit, Florentin Glötzl and Ernest Aigner compiled a large-scale data set consisting of 420,850 journal articles published between 1956 and 2016 in 433 economics journals to further deepen our understanding of the stratified nature of economics. Their article demonstrates how the internal structure of the discipline became more concentrated in a variety of dimensions over the last decades.

Overall, the articles collected in this issue of Science in Context demonstrate how social, academic, and paradigmatic power is distributed within economics. They provide insights into how the field developed since the financial crisis and how inequalities in terms of research practices, theoretical orientations, gender, or social origin are maintained over time and partially even strengthened by the emergence of new institutions and practices. One recent example of this impact of institutions and practices is analyzed in the contribution by Marcella Corsi, Carlo D'Ippoliti, and Giulia Zacchia. Comparing the behavior and profile of candidates for economics professorships before and after the introduction of a bibliometric-based research evaluation system in Italy, the authors find a profound change in recruiting practices, gender diversity, and paradigmatic orientation. Another example is the study of Tim Winzler which shows that inequalities in economics can be traced back to the education and socialization of economists. By analyzing students' narratives and illuminating their social backgrounds, Winzler demonstrates how economics students' habitus is shaped by established practices in economics education as well as by neoliberal society at large.

All contributions have in common that they provide empirical evidence on persistence and change in contemporary economics. In this context possible changes in the discipline's research focus induced by the advent of the financial crisis of 2007-2008 are of special interest as they allow us to evaluate whether exogenous shocks - such as the crisis - actually have a real impact on a discipline's development. Drawing a topical map of the structure of German economics between 
2005 and 2014, Ulrike Jacob and Oliver Brust can indeed show that topical turnover is higher at the periphery of the crisis-ridden discipline, serving as a gateway for new economic ideas. However, the authors are reluctant to concede that the crisis had a large impact on contemporary economics, since classic topics remain at the very center of the discipline with their position being seemingly unaffected by the crisis. In this sense, their study could be understood as another example demonstrating the overall stability of economics and the general reluctance of scientific paradigms to confront their established blind-spots. This is very much in line with the other articles in this special issue which describe contemporary economics as academically more stratified and isolated than any of the other social sciences. In the interpretation of Glötzl and Aigner, economics can be understood as an intellectually "locked-in" profession with dominant players acting as barriers for new ideas and thus inhibiting real academic change, a situation which is even further strengthened by certain practices and institutions such as evaluative bibliometrics which tend to diminish demographic diversity and intellectual pluralism (see the articles by Aistleitner et al., and Corsi et al.).

All in all, we hope that the contributions in this topical issue further encourage the dialogue between economics, sociology, science studies, and the history of economic thought on the nature of economics as an academic discipline. As each profession comes with a specific disciplinary identity (Hyland 2012), they all conceptualize their contributions from different perspectives and tend to ask their own set of questions. In this context, learning from each other seems crucial for the future prosperity of the field. Thus, future scholarship should aim to derive its research questions directly from this intersection of different fields. Additionally, it would profit from comparing developments in economics more thoroughly with those found in other disciplines to distinguish economics-specific patterns from those found in any science. And finally, it should more often employ quantitative methods and exploit novel forms of data. Along these lines we hope that this topical issue inspires other researchers to take up our recommendations and that research on economics and economic knowledge will be pushed forward.

Acknowledgments. This topical issue is the result of a joint effort of involved authors, the editorial team of Science in Context, and the guest editors. The guest editors would thereby like to express their gratitude to the contributors as well as the editorial team of Science in Context, for all the effort they put into this endeavor. Research in this topical issue was supported by the Institute for New Economic Thinking (INET), the Forschungsinstitut für gesellschaftliche Weiterentwicklung (FGW), as well as the Economic and Social Research Council (ESRC).

\section{References}

Blaug, Mark. 2001. "No History of Ideas, Please, We're Economists.” Journal of Economic Perspectives 15(1):145-164.

Boldyrev, Ivan, and Ekaterina Svetlova. 2016. Enacting Dismal Science: New Perspectives on the Performativity of Economics. London: Palgrave Macmillan.

Callon, Michel. 1998. "Introduction: The Embeddedness of Economic Markets in Economics." In The Laws of the Markets, edited by Michel Callon, 1-57. Oxford: Blackwell.

Cherrier, Beatrice, and Andrej Svorenčík. 2018. "The Quantitative Turn in the History of Economics: Promises, Perils and Challenges." Journal of Economic Methodology 25(4):367-377.

Colander, David, Richard P.F. Holt, and J. Barkley Rosser Jr. 2004. “The Changing Face of Mainstream Economics.” Review of Political Economy 16(4):485-499.

Dobusch, Leonhard, and Jakob Kapeller. 2009. “'Why is Economics Not an Evolutionary Science?' New Answers to Veblen's Old Question.” Journal of Economic Issues 43(4):867-898.

Edwards, José, Yann Giraud, and Christophe Schinckus. 2018. "A Quantitative Turn in the Historiography of Economics?" Journal of Economic Methodology 25(4):283-290.

Fourcade, Marion. 2009. Economists and Societies: Discipline and Profession in the United States, Britain, and France, 1890 s to 1990s. Princeton: Princeton University Press.

Fourcade, Marion. 2018. "Economics: The View from Below." Swiss Journal of Economics and Statistics 154(5):1-9.

Fourcade, Marion, Etienne Ollion, and Yann Algan. 2015. "The Superiority of Economists." Journal of Economic Perspectives 29(1):89-114.

Godechot, Olivier. 2018. “The Laws of Economics:' Economic Devices, Economics, Economists, and the Making of the Economy." Economic Sociology: The European Electronic Newsletter 19(2). 
Hamermesh, Daniel S. 2018. "Citations in Economics: Measurement, Uses, and Impacts." Journal of Economic Literature 56(1):115-156.

Heckman, James J., and Sidharth Moktan. 2018. "Publishing and Promotion in Economics: The Tyranny of the Top Five." INET Working Paper, No. 82.

Hirschman, Daniel, and Elizabeth Popp Berman. 2014. "Do Economists Make Policies? On the Political Effects of Economics." Socio-Economic Review 12(4):779-811.

Hyland, Ken. 2012. Disciplinary Identities: Individuality and Community in Academic Discourse. Cambridge: Cambridge University Press.

Kapeller, Jakob, Stephan Pühringer, Katrin Hirte, and Walter O. Ötsch. 2016. Ökonomie! Welche Ökonomie? Stand und Status der Wirtschaftswissenschaften. Marburg: Metropolis.

MacKenzie, Donald. 2006. An Engine, Not a Camera: How Financial Models Shape Markets. Cambridge: MIT Press.

Maeße, Jens, Hanno Pahl, and Jan Sparsam. 2017. Die Innenwelt der Ökonomie: Wissen, Macht und Performativität in der Wirtschaftswissenschaft. Wiesbaden: Springer VS.

McCloskey, Deirdre N. 1985. The Rhetoric of Economics. Madison: University of Wisconsin Press.

Mirowski, Philip. 1989. More Heat than Light: Economics as Social Physics, Physics as Nature's Economics. Cambridge: Cambridge University Press.

Morgan, Mary S. 2012. The World in the Model: How Economists Work and Think. Cambridge: Cambridge University Press.

Pahl, Hanno. 2018. Genese, Konsolidierung und Transformation der neoklassischen Wissenschaftskultur: Zur Konturierung einer Soziologie der Wirtschaftswissenschaften. Wiesbaden: Springer VS.

Schmidt-Wellenburg, Christian, and Frédéric Lebaron. 2018. "Economists, Politics, and Society: New Insights from Mapping Economic Practices Using Field-Analysis." Historical Social Research 43(3).

Jakob Kapeller is a professor for socioeconomics at the University of Duisburg-Essen (Germany) and heads the Institute for Comprehensive Analysis of the Economy at Johannes Kepler University Linz (Austria). His research interests are focused on socio-economic change from a political economy perspective and relate to the history of ideas, the philosophy of the social sciences, distributional issues, and heterodox economics.

Daniel Meyer is a doctoral researcher at the Max Planck Institute for the Study of Societies in Cologne, Germany. His research interests include economic sociology, higher education, labor markets, organizations, and science studies. His dissertation investigates how business schools shape students' career aspirations.

Cite this article: Kapeller Jakob and Daniel Meyer. 2019. "Introduction: Change and Persistence in Contemporary Economics," Science in Context 32:357-360. doi:10.1017/S0269889720000010 